\title{
Attention Deficit Hyperactivity Disorder and Executive Functions
}

\author{
Cardoso Moreno MJ* \\ Department of Psychology and Sociology, University of Zaragoza, Spain
}

Received: 啙 July 23, 2018; Published: 跳 July 25, 2018

*Corresponding author: Cardoso Moreno MJ, Department of Psychology and Sociology, University of Zaragoza, Spain, Tel: 34976765444; Email: mcarmor@unizar.es

\begin{abstract}
Attention deficit hyperactivity disorder (ADHD), a common neurobehavioral disorder with onset in childhood, is characterized by developmentally inappropriate levels of hyperactivity, motor impulsivity, emotional and social responses, a general lack of inhibition and pervasive inattention. In many studies, ADHD has been conceptualized as resulting from dysfunction in the frontostriatal region of the prefrontal cortex and manifesting as observable deficits in higher-order executive function. This conceptualization of ADHD presumes that the essential impairment in ADHD is a deficit in behavioural response inhibition leading to secondary impairments in Executive Functions (EF).
\end{abstract}

Abbreviations: ADHD: Attention Deficit Hyperactivity Disorder; EF: Executive Functions; IFC: Inferior Prefrontal Cortex; MRI: Magnetic Resonance Imaging

\section{Introduction}

The core symptoms of inattention, impulsivity, and motor activity are highly correlated with neuroanatomical differences [1] identified discrete categories of function of the frontal lobes, one being executive functioning. They indicated, however, that the executive category does not refer solely to a central executive system and that the frontal lobes do not have a unitary organizing role. Rather, they described impairments in a multitude of anatomical and functional attentional control processes that are interrelated. This argument supports the view that the frontal lobes work in tandem with many other areas of the brain. Executive function has many dimensions, including choosing, planning, programming, implementing, monitoring, and adjusting or ending a volitional act. Attention is another facet of executive function. Attention is selective and well sustained when functioning appropriately. Attention is discriminating and, in some ways, biased toward achieving an end or desired goal [2].

On the other hand, several authors have proposed that symptoms of attention deficit/ hyperactivity disorder (ADHD) arise from a primary deficit in a specific EF domain such as response inhibition or working memory or a more general weakness in executive control [3-6]. This hypothesis is based on the observation that prefrontal lesions sometimes produce behavioural hyperactivity, distractibility, or impulsivity, as well as deficits on EF tasks $[7,8]$. EF weaknesses may be one of several important components in a multifactorial neuropsychological model of ADHD. Neuroimaging studies in children with ADHD have shown consistent abnormalities relative to control subjects in latedeveloping inferior front ostriatal and frontocerebellar circuitries that mediate these cognitive control functions that are impaired in the disorder. Thus, structural magnetic resonance imaging (MRI) studies found reduced volume and cortical thickness in inferior prefrontal cortex (IFC) but also other frontal brain regions, as well as parietotemporal regions, the basal ganglia, the splenium of the corpus callosum, and the cerebellum $[9,10,11]$

Other work carries out by Goldman-Rakic and colleagues [12] emphasized the role of a frontoparietal system in visual attention/ working memory tasks and showed the role and anatomy of the dopaminergic components of this circuit. Longitudinal imaging studies have provided evidence that the structural abnormalities in these late-developing fronto-striato-cerebellar and frontoparietal systems are due to a late structural maturation of these regions [3]. Thus, the peak of cortical thickness maturation has been shown to be delayed in children with ADHD compared with healthy peers by an average of 3 years, with some regions, including frontal and temporal areas, being delayed in their cortical maturation by up to 4 to 5 years [13]. Several studies conclude that dorsal frontostriatal, orbitofronto-striatal, and fronto-cerebellar circuits are involved in ADHD. These circuits interact through spiralling loops in the striatum and connections from the cerebellum to the prefrontal cortex and the striatum, although there are more connections within than between circuits.

Dysfunction in any of these circuits might cause symptoms of ADHD. Dysfunction of the prefrontal cortex is likely to result in a reduced ability to exert control [14]. Dysfunction in dorsal striatum might lead to differences in the ability to predict what events are going to occur, whereas dysfunction in ventral striatum is more 
likely to lead to deficits in motivation and reward processing. Dysfunction of the cerebellum is likely associated with problems in the ability to predict when events are going to occur and other problems with timing. The implication of this is that, although this wide range of neurobiological differences can lead to symptoms of ADHD, the cognitive effects of dysfunction at the various levels might be quite different. According to previous studies, executive function deficits are suggested to be an important component of attention-deficit hyperactivity disorder (ADHD) [15]. In many studies ADHD has been associated with weaknesses in several key EF domains. EF difficulties appear to be one of several important weaknesses that compromise the overall neuropsychological etiology of ADHD [16,17].

Childhood ADHD is characterized by structural and functional deficits compared to healthy children. This occurs in predominantly inferior but also medial and dorsolateral prefrontal cortices, anterior cingulate, the basal ganglia, cerebellum, and temporo-parietal brain regions and their functional and structural interconnectivity, causing poor top-down control over inhibitory, attention, and timing functions. It has been suggested that neurobiological dysfunction in any of these circuits can lead to symptoms of ADHD. Deficits in the prefrontal cortex could affect control systems directly. Also, problems in the circuits relaying information to the prefrontal cortex could lead to reduced signalling for control [18]. In both scenarios, behavioural control would be compromised, leading to behavioural changes, such as impulsive and inattentive behaviour. We have taken this data into account to design our intervention program. Strategies that address executive function processes therefore provide a starting point for improving academic performance. When students use executive function strategies, they become more efficient and they begin to improve academically.

To build their motivation and persistence, students need to understand their strengths and weaknesses, which strategies work well for them, as well as why, where, when, and how to apply specific strategies. This understanding, referred to as metacognition, or the ability to think about their own thinking and learning, underlies students' use of executive function processes. Students need to learn when to use which strategies and in what contexts. They also need to recognize that not all strategies work for all tasks and all content areas. In other words, strategies need to fit well with the student's learning style as well as the task content and the context. Preliminary evidence that such dissociation might be possible comes from [19]. They used principal component analysis to show that three separable components contributed to the variance in their neuropsychological task battery. These components corresponded to timing, cognitive control (termed inhibition in their report), and reward (termed delay aversion). Of the 77 children with ADHD included in this study, 55 could be identified as having a deficit on one of these components, and the overlap between components was no greater than would be expected by chance.

This suggests that these components might indeed rely on neurobiological separable systems. However, these data were based on computer testing only, so no direct measures of neurobiology were available. Nonetheless, the cognitive areas with which these components are related suggest they might map onto the three circuits described: timing is associated with fronto-cerebellar loops, cognitive control with dorsal frontostriatal loops, and reward with orbitofronto-striatal loops. There might be at least three neurobiological pathways to ADHD, involving disruption of dorsal frontostriatal, orbitofronto-striatal, or fronto-cerebellar circuits. However, there might be other circuits involved. For example, the amygdala has reciprocal connections with the prefrontal cortex and has been suggested to play a role in ADHD [20]. Fronto-amygdalar circuits could be involved in attributing emotional value to events, and inputs from amygdala could affect the recruitment of prefrontal control. Only indirect evidence of the involvement of this circuitry in ADHD comes from the observation of differences in medial temporal lobe structures in ADHD [21,22].

Students' attention and their ability to engage actively in the learning process are associated with their ability to regulate their emotions in and outside the classroom [23-25]. The effects of emotion on the learning process range along a continuum. Specifically, extreme emotional reactions (e.g., anxiety, anger) often disrupt students' attention and ability to stay on task as well as their ability to learn and remember new information [26,27]. In contrast, moderate emotional arousal has a positive influence on students' attention and executive function processes including working memory, cognitive flexibility, and inhibition [28,29]. More specifically, the relationship between anxiety and performance is characterized by an inverted U-shaped curve, e.g., test performance is often poor when students either are not anxious and have consequently not studied or are excessively anxious which interferes with attention, working memory, and overall performance [30]. Similarly, negative moods disrupt attention, concentration, memory and processing speed.

The SMARTS program focuses on promoting resilience and academic success by teaching executive function strategies and building metacognitive awareness and persistence in all students, and particularly in students with learning difficulties [31-33]. Gender is also considered in ADHD studies [34] did not find any significant gender differences in children diagnosed with ADHD. However, some authors have reported some gender differences; boys show a tendency to be more impulsive and have a poorer motor control than girls [34-36]. Information about the child's neuropsychological, cognitive, academic, and psychosocial status forms the basis for designing integrated intervention and treatment plans for children and adolescents with brain-related disorders. Efforts to develop models of neuropsychological intervention have been expanding in recent years. In an effort to provide a framework for linking assessment to interventions The Amsterdam attention and memory training program is based on a modified version of the Sohlberg and Mateer model [37].

The program contains elements that address: process training for attention and memory; metacognitive strategy training; social contact and support [38] found that, following an executive intervention treatment, children showed an improvement on neuropsychological measures of sustained and selective attention; 
a modest improvement on memory tests, and improvement on teacher and parent reports of behaviours, learning and socialemotional factors. Other interventions that promote executive control skills have revealed to improve behaviour in children with ADHD [39]. It is increasingly recognized that ADHD is a lifelong disorder and the focus on mental health interventions needs to be long-term: individualized plans that require ongoing evaluation, modification, and implementation, over months and years. Taking this data into account, future research should focus also on the elaboration and assessment of intervention programs taking as a starting point the alteration in executive functions in children with ADHD.

\section{References}

1. Stuss DT, Alexander MP (2007) Is there a dysexecutive system? Philosophical Transactions of the Royal Society of London. Series B Biological Sciences 362: 901-915.

2. Samango-Sprouse C (1999) Frontal lobe development in childhood. The human frontal lobes: Functions and disorders Guildford Press, New York, USA, pp. 584-604.

3. Barkley RA (1997) Behavioral inhibition, sustained attention, and executive function: Constructing a unified theory of ADHD. Psychological Bulletin 121(1): 65-94.

4. Castellanos FX, Tannock R (2002) Neuroscience of attention-deficit/ hyperactivity disorder: The search for endophenotypes. Nature Reviews Neuroscience 3: 617-628.

5. Pennington BF, Ozonoff S (1996) Executive functions and developmental psychopathology. Journal of Child Psychology and Psychiatry 37: 51-87.

6. Schachar R, Mota VL, Logan GD, Tannock R, Klim P, et al. (2000) Confirmation of an inhibitory control deficit in attention-deficit/ hyperactivity disorder. Journal of Abnormal Child Psychology 28: 227235.

7. Fuster JM (1997) The Prefrontal Cortex: Anatomy, Physiology and Neuropsychology of the Frontal Lobe (2nd Ed.). Raven, New York, USA.

8. Stuss DT, Benson DF (1986) The Frontal Lobes. Raven Press, New Yor, USA.

9. Krain AL, Castellanos FX (2006) Brain development and ADHD. Clinical Psychology Review 26(4): 433-444.

10. Mackie S, Shaw P, Lenroot R, Pierson R, Greenstein DK, et al. (2007) Cerebellar development and clinical outcome in attention deficit hyperactivity disorder. American Journal of Psychiatry 164: 647-655.

11. Shaw P, Lerch J, Greenstein D, Sharp W, Clasen L, et al. (2006) Longitudinal mapping of cortical thickness and clinical outcome in children and adolescents with attention-deficit/hyperactivity disorder. Archives of General Psychiatry 63: 540-549.

12. Chafee MV, Goldman-Rakic, PS (1998) Matching patterns of activity in primate prefrontal area $8 \mathrm{a}$ and parietal area $7 \mathrm{ip}$ neurons during a spatial working memory task. Journal of Neurophysiology 79(6): 2919-2940.

13. Shaw P, Eckstrand K, Sharp W, Blumenthal J, Lerch JP, et al. (2007) Attention-deficit/hyperactivity disorder is characterized by a delay in cortical maturation. Proceeding of the National Academy of Sciences of the United States of America 104: 19649-19654.

14. Casey B J, Nigg JT, Durston S (2007) New potential leads in the biology and treatment of attention deficit-hyperactivity disorder. Current Opinion in Neurology 20(2): 119-124.

15. Holmes J, Gathercole SE, Place M, Alloway TP, Elliott JG, et al. (2010) The Diagnostic Utility of Executive Function Assessments in the Identification of ADHD in Children. Child and Adolescent Mental Health 15: 37-43.

16. Willcutt EG, Doyle AE, Nigg JT, Faraone SV, Pennington BF, et al.
(2005) Validity of the executive function theory of attention-deficit/ hyperactivity disorder: A meta-analytic review. Biological Psychiatry 57: 1336-1346.

17. Toplak ME, Bucciarelli SM, Jain U, Tannock R (2009) Executive functions: performance-based measures and the behavior rating inventory of executive function (BRIEF) in adolescents with attention deficit/ hyperactivity disorder (ADHD). Child Neuropsychology 15: 53-72.

18. Sonuga-Barke E, Bitsakou P, Thompson M (2010) Beyond the dual pathway model: Evidence for the dissociation of timing, inhibitory, and delay-related impairments in attention-deficit/hyperactivity disorder. Journal of American Academy of Child and Adolescence Psychiatry 49: 345-355.

19. Nigg JT, Casey BJ (2005) An integrative theory of attentiondeficit/hyperactivity disorder based on the cognitive and affective neurosciences. Development and Psychopathology 17: 785-806.

20. Castellanos FX, Giedd JN, Marsh WL, Hamburger SD, Vaituzis AC, et al. (1996) Quantitative brain magnetic resonance imaging in attentiondeficit hyperactivity disorder. Archives of General Psychiatry 53(7): 607-616.

21. Carmona S, Vilarroya O, Bielsa A, Tremols V, Soliva JC, et al. (2005) Global and regional gray matter reductions in ADHD: A voxelbased morphometric study. Neuroscience Letters 389(2): 88-93.

22. Brooks R (1991) The self-esteem teacher: Seeds of selfesteem. Treehaus, New York, USA.

23. Tangney JP, Baumeister RF, Boone AL (2004) High self-control predicts good adjustment, less pathology, better grades, and interpersonal success. Journal of Personality 72: 271-324.

24. Goldberg E (2001) The executive brain: Frontal lobes and the civilized mind. New York: Oxford University Press, USA.

25. Stein J (2010) Emotional self-regulation: A critical component of executive function. Promoting executive function in the classroom New York: Guilford Press, USA, pp. 175-201.

26. Gross JJ (2007) Handbook of emotion regulation. Guilford Press, New York, USA.

27. Goleman D (1995) Emotional intelligence. Bantam Books, New York, USA.

28. Gray L, Meltzer C, Upton M (2008) The SMARTS peer mentoring program: Fostering self understanding and resilience across the grades. Paper presented at the 23rd Annual Learning Differences Conference, Harvard Graduate School of Education, Cambridge, MA.

29. Meltzer L, Reddy R, Brach E, Kurkul K, Basho S (2011) Self-concept, motivation, and executive function: Impact of a peer mentoring program. Paper presented at the Pacific Coast Research Conference San Diego, CA.

30. Meltzer LJ (2014) Teaching executive function processes: Promoting metacognition, strategy use, and effort. Executive Functioning Handbook New York, USA pp. 445-474.

31. Gomez R (2007) Testing gender differential item functioning for ordinal and binary scored parent rated ADHD symptoms. Personality and Individual Differences 42: 733-742.

32. Cole WR, Mostofsky SH, Larson JC, Denckla MB, Mahone EM (2008) Agerelated changes in motor subtle signs among girls and boys with ADHD. Neurology 71(19): 1514-1520.

33. Sohlberg M, Mateer C (2001) Cognitive Rehabilitation. An Integrative Neuropsychological Approach. New York: Guilford Press, USA.

34. Hooft I, Andersson K, Sejersen T, Bartfai A, von Wendt L, et al. (2003) Attention and memory training in children with acquired brain injuries. Acta Paediatrica 92: 935-940.

35. Dawson P, Guare R (2004) Executive Skills in Children and Adolescents: a practical guide to assessment and intervention. Canada: The Guilford Press. 
36. Brickencamp R, Zilmer E (1999) The d2 Test of Attention. Boston: Hogrefe \& Huber.

37. Brieber S, Neufang S, Bruning N, Kamp-Becker I, Remschmidt H, et al. (2007) Structural brain abnormalities in adolescents with autism spectrum disorder and patients with attention deficit/hyperactivity disorder. Journal of Child Psychology and Psychiatry 48(12): 1251-1258.
38. Plessen KJ, Bansal R, Zhu H, Whiteman R, Amat J, et al. (2006) Hippocampus and amygdala morphology in attention-deficit/ hyperactivity disorder. Archives of General Psychiatry 63: 795-807.

39. Wilson BA, Emslie H, Evans JJ, Alderman N, Burgess PW, et al. (1996) Behavioural Assessment of the Dysexecutive Syndrome (BADs). Pearson, London, UK.

\section{ISSN: 2574-1241}

DOI: 10.26717/BJSTR.2018.07.001477

Cardoso Moreno MJ. Biomed J Sci \& Tech Res

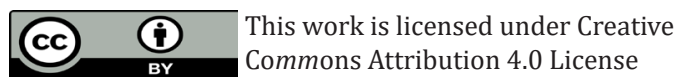

Submission Link: https://biomedres.us/submit-manuscript.php

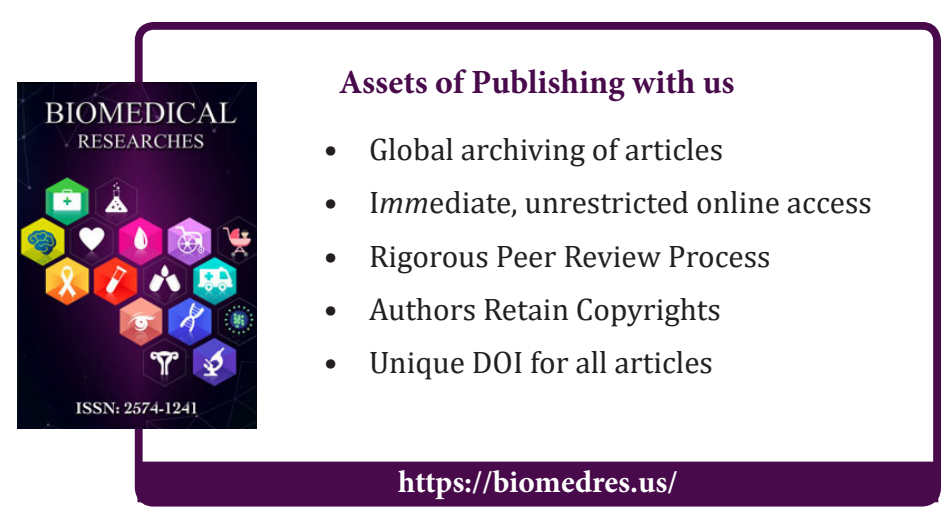

